\title{
American Society for Enhanced Recovery and Perioperative Quality Initiative Joint Consensus Statement on Nutrition Screening and Therapy Within a Surgical Enhanced Recovery Pathway
}

\author{
Paul E. Wischmeyer, MD, EDIC,* Franco Carli, MD, MPhil,† David C. Evans, MD, FACS, $\neq$ \\ Sarah Guilbert, RD, LDN, CNSC,§ Rosemary Kozar, MD, PhD, ॥ Aurora Pryor, MD, FACS, $\Uparrow$ \\ Robert H. Thiele, MD,\# Sotiria Everett, EdD, RD, ${ }^{* *}$

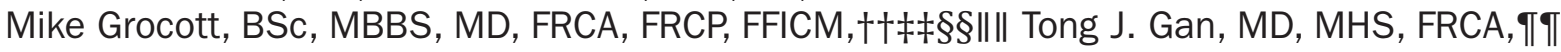 \\ Andrew D. Shaw, MB, FRCA, FCCM, FFICM,\#\#*** Julie K. M. Thacker, MD, ††† \\ and Timothy E. Miller, MB, ChB, FRCA, 㧊 for the Perioperative Quality Initiative (POQI) 2 Workgroup
}

\begin{abstract}
Perioperative malnutrition has proven to be challenging to define, diagnose, and treat. Despite these challenges, it is well known that suboptimal nutritional status is a strong independent predictor of poor postoperative outcomes. Although perioperative caregivers consistently express recognition of the importance of nutrition screening and optimization in the perioperative period, implementation of evidence-based perioperative nutrition guidelines and pathways in the United States has been quite limited and needs to be addressed in surgery-focused recommendations. The second Perioperative Quality Initiative brought together a group of international experts with the objective of providing consensus recommendations on this important topic with the goal of (1) developing guidelines for screening of nutritional status to identify patients at risk for adverse outcomes due to malnutrition; (2) address optimal methods of providing nutritional support and optimizing nutrition status preoperatively; and (3) identifying when and how to optimize nutrition delivery in the postoperative period. Discussion led to strong recommendations for implementation of routine preoperative nutrition screening to identify patients in need of preoperative nutrition optimization. Postoperatively, nutrition delivery should be restarted immediately after surgery. The key role of oral nutrition supplements, enteral nutrition, and parenteral nutrition (implemented in that order) in most perioperative patients was advocated for with protein delivery being more important than total calorie delivery. Finally, the role of often-inadequate nutrition intake in the posthospital setting was discussed, and the role of postdischarge oral nutrition supplements was emphasized. (Anesth Analg 2018;XXX:00-00)
\end{abstract}

$\mathrm{P}$ erioperative malnutrition has proven to be challenging to define, diagnose, and treat. Despite these challenges, it is well known that suboptimal nutritional status is a strong independent predictor of poor postoperative outcomes. ${ }^{1}$ Malnourished surgical patients have significantly higher postoperative mortality, morbidity, length of stay (LOS), readmission rates, and increased hospital costs. ${ }^{2-4}$ It is estimated that $24 \%-65 \%$ of patients undergoing surgery are at nutrition risk. ${ }^{3,5-7}$ Additionally, recent prospective observational data indicate that undernourished patients or patients at risk of malnutrition are twice as likely to be readmitted within 30 days after elective colorectal surgery. ${ }^{8}$ As defined by the National Surgical Quality Improvement Program, malnutrition is among the few modifiable preoperative risk factors associated with poor surgical outcomes, including mortality, in surgical patients. ${ }^{9,10}$ This risk of malnutrition is often most
From the *Department of Anesthesiology, Duke University School of Medicine, Durham, North Carolina; †McGill University, Montreal, Québec, Canada; $¥$ Department of Surgery, Division of Trauma, Critical Care, and Burn, Ohio State University, Columbus, Ohio; §Duke University Hospital, Durham, North Carolina; ॥University of Maryland School of Medicine, Baltimore, Maryland; \Department of Surgery, Stony Brook Medicine, Stony Brook, New York; \#Departments of Anesthesiology and Biomedical Engineering, Divisions of Cardiac, Thoracic, and Critical Care Anesthesiology, University of Virginia School of Medicine, Charlottesville, Virginia; ${ }^{*}$ Nutrition Division, Department of Family, Population, Preventive Medicine, Stony Brook Medicine, Stony Brook, New York; ††Respiratory and Critical Care Research Area, National Institute of Health Research Biomedical Research Centre, University Hospital Southampton, Southampton, United Kingdom; ‡¥Southampton National Health Service Foundation Trust, Integrative Physiology and Critical Illness Group, Southampton, United Kingdom; §§Clinical and Experimental Sciences, Faculty of Medicine, University of Southampton, Southampton, United Kingdom; IIIMorpheus Collaboration, Department of Anesthesiology, Duke University School of Medicine, Durham, North Carolina; ๆqDepartment of Anesthesiology, Stony Brook

Copyright (c) 2017 International Anesthesia Research Society DOI: 10.1213 /ANE.0000000000002743
University School of Medicine, Stony Brook, New York; \#\#Vanderbilt University School of Medicine, Nashville, Tennessee; ***Department of Anesthesiology, Vanderbilt University Medical Center, Nashville, Tennessee; and +††Department of Surgery, Division of Advanced

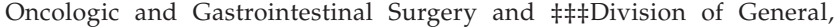
Vascular and Transplant Anesthesia, Duke University Medical Center, Durham, North Carolina.

Accepted for publication October 27, 2017.

Funding: The Perioperative Quality Initiative (POQI) meeting received financial assistance from the American Society for Enhanced Recovery (ASER)

Conflicts of Interest: See Disclosures at the end of the article.

Supplemental digital content is available for this article. Direct URL citations appear in the printed text and are provided in the HTML and PDF versions of this article on the journal's website (www.anesthesia-analgesia.org).

For the Perioperative Quality Initiative (POQI) 2 Workgroup, see Supplemental Digital Content, Appendix 1, http:/ /links.lww.com/AA/C160.

Reprints will not be available from the authors.

Address correspondence to Timothy E. Miller, MB, ChB, FRCA, Division of General, Vascular and Transplant Anesthesia, Duke University Medical Center, Box 3094, Durham, NC 27710. Address e-mail to timothy.miller2@duke.edu. 
significant after major gastrointestinal (GI) and oncologic surgery, groups commonly focused on in enhanced recovery pathways (ERPs). ${ }^{2-4}$ Further, appropriate perioperative nutritional therapy has been shown to specifically improve perioperative outcomes in GI/oncologic surgery, where the greatest risk of baseline malnutrition risk ( $65 \%$ ) occurs. ${ }^{3,6,11}$ In surgical patients overall, perioperative nutrition interventions can improve surgical outcomes and reduce infectious morbidity and mortality. ${ }^{12}$ There is a long history of randomized controlled trials (RCTs) and meta-analyses demonstrating preoperative nutrition (regardless of route of administration) in malnourished patients before GI surgery reduces postoperative morbidity by $20 \%{ }^{13}$ Postoperative nutritional support is vital in maintaining nutritional status during the catabolic postoperative period and underscored by evidence for early and sustained feeding after surgery as part of ERP protocols. ${ }^{14-16}$ In fact, the advancement of oral intake has been identified as an independent determinant of early recovery after colorectal surgery. ${ }^{17}$ Some of the most striking recent data on the role of nutrition delivery in the perioperative period have demonstrated in patients undergoing oncologic surgery in an ERP, delivery of nutrition on the first postoperative day is an independent predictor of postoperative survival at 5 years. ${ }^{18}$

Unfortunately, recent evidence reveals that significant deficiencies in nutritional screening and intervention in US colorectal and oncologic surgical patients with only $\sim 1$ in 5 hospitals currently utilizing a formal nutrition screening process. ${ }^{19}$ This is surprising as $83 \%$ of US surgeons believe that existing data support preoperative nutrition optimization to reduce perioperative complications. ${ }^{19}$ However, only $\sim 20 \%$ of US GI/ oncologic surgery patients receive any nutritional supplements in the preoperative or postoperative setting. ${ }^{19}$ Overall US surgeons recognized both the importance of proper perioperative surgical nutritional support and the potential value to patient outcomes. Despite these beliefs, these data confirm poor implementation of evidence-based nutrition practices in major surgery. ${ }^{19}$
A summary of the current challenges and known benefits of perioperative nutrition interventions are shown in Figure 1. The urgency of improving perioperative nutrition practices is underscored by strong recommendations from international nutrition society guidelines endorsing perioperative nutrition optimization. ${ }^{21-24}$ However, limited surgical/perioperative society guidelines exist on how to optimally screen surgical patients for malnutrition and optimize nutritional status in the perioperative period, particularly within an ERP. Thus, we sought to define and answer important questions related to perioperative nutrition in patients undergoing surgery within the context of an ERP.

\section{METHODS/DESIGN}

This consensus process utilized a modified Delphi method as described previously ${ }^{25}$ and processes detailed by the National Institute for Health and Care Excellence. ${ }^{26}$ The Perioperative Quality Initiative (POQI) is a previously described collaborative of diverse international experts in anesthesia, nursing, nutrition, and surgery tasked to develop consensus-based recommendations in ERP. ${ }^{25,27}$ The format for grading of recommendations is included in Table 1 . The participants in the POQI consensus meeting were recruited based on their expertise in the principles of enhanced recovery after surgery/ERP and met in Stony Brook, New York, on December 2-3, 2016.

\section{RESULTS}

- The formal consensus recommendations are described in Table 2.

- Key perioperative nutrition questions addressed in this consensus statement are summarized in Supplemental Digital Content, Appendix 1, http:/ / links.lww.com/AA/C160.

- A summary of key "take-away" recommendations is summarized in Figure 2.

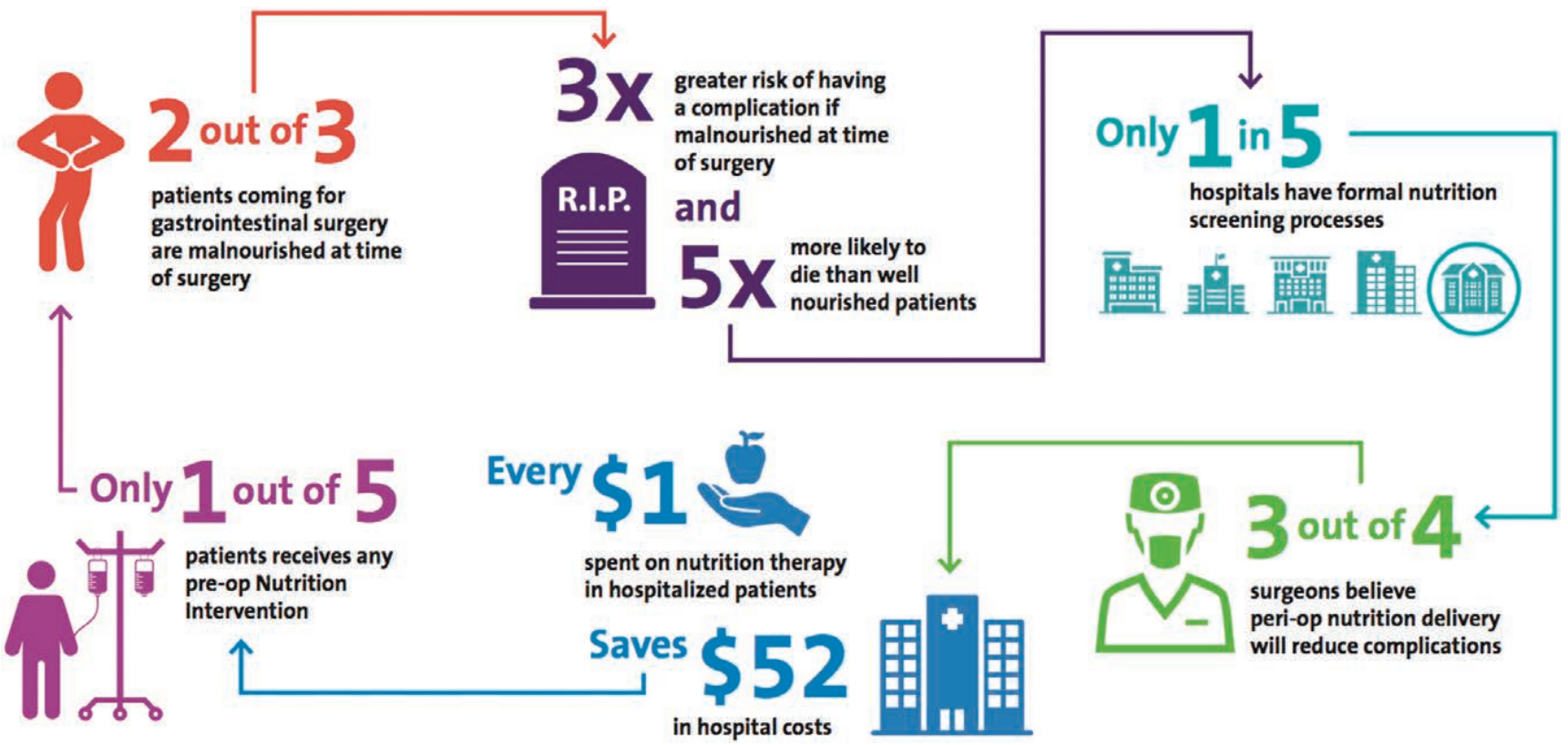

Figure 1. Facts and data for perioperative nutrition screening and therapy. Data drawn from Awad and Lobo ${ }^{6}$, Williams and Wischmeyer ${ }^{19}$, and Philipson et al. ${ }^{20}$ R.I.P. indicates rest in peace. 
Table 1. Format of Recommendations in POQI Guidelines (From NICE Guidelines)

Strength of Recommendations ${ }^{\text {a }}$

\begin{tabular}{|c|c|}
\hline Strength & Definition \\
\hline Strongly recommend & $\begin{array}{l}\text { Committee believes that the evidence is } \\
\text { strong, supported by numerous high-quality } \\
\text { prospective randomized trials. }\end{array}$ \\
\hline Recommend & $\begin{array}{l}\text { Evidence supporting the practice is not as } \\
\text { strong, based on high-quality prospective and } \\
\text { retrospective studies. Committee feels that } \\
\text { benefits of the intervention outweigh the risk } \\
\text { for the majority of patients. }\end{array}$ \\
\hline Consider & $\begin{array}{l}\text { There is a lack of quality research to make a } \\
\text { recommendation. Committee feels that the } \\
\text { practice is safe and likely to be effective } \\
\text { based on expert opinion. }\end{array}$ \\
\hline
\end{tabular}

Abbreviations: NICE, National Institute for Health and Care Excellence; POQI, Perioperative Quality Initiative.

aBased on NICE guidelines for strength of recommendations.

\section{Preoperative Screening}

Screening for malnutrition before major surgery is essential as it can identify patients at risk of malnutrition who may benefit from a nutritional intervention preoperatively. Numerous screening tools have been validated for use in already hospitalized patients, yet there is no consensus related to the optimal screening tool in the preoperative patient. After literature review, we developed and proposed the perioperative nutrition screen (PONS).

As shown in Figure 3, the PONS is a modified version of the malnutrition universal screening too ${ }^{28}$ that has been altered for use perioperatively. The PONS determines the presence of nutrition risk based on a patient's body mass index (BMI), recent changes in weight, reported recent decrease in dietary intake, and preoperative albumin level. In addition, the PONS includes evaluation of preoperative albumin level, as this is a predictor of postoperative complications, including morbidity/mortality. ${ }^{28-32}$

BMI assessment and recent unplanned weight loss are criteria used in several malnutrition screening tools. ${ }^{33,34}$ A BMI level indicative of underweight $\left(<18.5 \mathrm{~kg} / \mathrm{m}^{2}\right.$ for adults $<65$ years old) has been shown to increase postoperative complications in a variety of surgical patients..$^{33-37}$ The PONS uses a higher number $\left(<20 \mathrm{~kg} / \mathrm{m}^{2}\right)$ for adults $>65$ years old because research indicates that the risk for allcause mortality increases starting at a BMI of $24 \mathrm{~kg} / \mathrm{m}^{2}$ for this age population and doubles when BMI is $<22 \mathrm{~kg} / \mathrm{m}^{2}$ for men and $<20 \mathrm{~kg} / \mathrm{m}^{2}$ for women. ${ }^{38}$ While this research was not related to surgical risk, it suggests that higher BMI threshold should be used when evaluating weight status of older adults. Regardless of BMI, unintentional weight loss has been associated with morbidity, functional decline, and negative postoperative outcomes. ${ }^{39,40}$ Reduced oral intake is determined by asking patients if they have been eating $<50 \%$ of their normal diet in the preceding week. Similar questions related to reduced oral intake have been used in short nutrition screens with high sensitivity and specificity in validation studies. ${ }^{41,42}$

The PONS includes the use of albumin because it is inexpensive, commonly obtained in perioperative testing, and a strong predictor of surgical risk/mortality. ${ }^{10,32}$ While it has long utilized as an indicator of malnutrition, studies have shown that albumin is neither specific nor sensitive enough to be the optimal malnutrition marker in most patient populations. ${ }^{43}$ Until a better marker is available, we recommend its use as a component of the preoperative nutrition screen.

The PONS can be easily administered and incorporated into an electronic medical record for efficient communication. The intent is that the PONS can be administered quickly ( $<5$ minutes) by nursing staff in surgical/preoperative clinics and results will be instantly uploaded into electronic medical record, automatically triggering a nutrition intervention if 1 or more positive responses on the PONS score are recorded. Patients who are identified as being at high nutrition risk on screening should be referred to a Registered Dietitian Nutritionist for a complete nutrition assessment and intervention. In situations where referrals to Registered Dietitian Nutritionists are not possible, oral nutritional supplements (ONSs) are recommended and will be discussed in the following preoperative intervention section.

Please see Supplemental Digital Content, Appendix 2, http://links.lww.com/AA/C160, for discussion of future preoperative assessment techniques for sarcopenia and role of vitamin D in surgery. Please see Supplemental Digital Content, Appendix 3, http:/ /links.lww.com/AA/C160, for discussion of obese patient considerations.

\section{Preoperative Intervention}

What Is the Role of Achieving Protein Delivery Goals in the Perioperative Period?. Protein requirements are elevated in states of stress, such as surgery, to account for the added demands of hepatic acute phase proteins synthesis, the synthesis of proteins involved in immune function, and wound healing. ${ }^{4}$ Although optimal protein intakes for surgery are currently not clearly defined, nonsurgical nutrition guidelines suggest that stressed patients should consume at least $1.2-2.0 \mathrm{~g}$ of protein $/ \mathrm{kg} / \mathrm{d} .^{22}$

Whey protein and casein are among the best quality proteins overall for muscle synthesis ${ }^{45}$ and to stimulate anabolism in patients with advanced cancer. ${ }^{46}$ Several studies have identified that consuming 25-35 g of protein in a single meal maximally stimulates muscle protein synthesis. ${ }^{47}$ Based on the evidence of this ceiling effect, an equal distribution of daily dietary protein across meals has been proposed. The idea being that the anabolic response to a single dose of amino acids can be compounded when repeated multiple times per day. ${ }^{48}$ Given the emerging findings to support an even distribution of daily protein intake in healthy populations and the evidence that substantive high-quality amino acids are required to stimulate a typical anabolic response in cancer patients, it seems reasonable to suggest that daily protein requirements for cancer patients be met through moderate protein ( 25-35 g) consumption at every meal.

\footnotetext{
When Should High-Protein ONSs, Enteral Nutrition, and Parenteral Nutrition Be Initiated Preoperatively?. We recommend that patients who are screened as being at nutritional risk before major surgery receive preoperative ONSs for a period of at least 7 days. This may be achieved with either of the following: immunonutrition (IMN, containing arginine/fish oil) or high-protein ONSs (2-3× a day, minimum of $18 \mathrm{~g}$ protein/dose). When oral nutrition
} 
Table 2. Consensus Statements and Recommendations

\section{Before Surgery}

1. We recommend screening of nutritional status before major surgery using a simple screening tool (via electronic medical record where possible) (see suggested/example tools in manuscript).

2. We propose the PONS questions for clinic-based perioperative nutrition screening

Does the patient have a low BMI $<18.5 \mathrm{~kg} / \mathrm{m}^{2}(<20$ in $>65$ y of age $)$ ?

- Has the patient experienced a weight loss $>10 \%$ in past 6 mo?

Has the patient had a reduced oral intake by $>50 \%$ in the past week? (and/or)

Does the patient have a preoperative serum albumin $<3.0 \mathrm{~g} / \mathrm{dL}$ ?

3. We recommend that if any screening questions in PONS score are positive for nutritional risk, that intervention and/or referral for formal nutrition assessment take place (see recommendation 6).

4. We suggest evaluation of lean body mass via CT scan, when available, to assist with nutritional risk prediction before surgery.

5. We recommend reaching an overall protein intake goal is more important than achieving a total calorie intake in the preoperative period with a recommended protein goal $>1.2 \mathrm{~g} / \mathrm{kg} / \mathrm{d}$.

6. We recommend that patients who are screened as being at nutritional risk before major surgery receive preoperative ONSs for a period of at least $7 \mathrm{~d}$. This may be achieved with either of the following:

- IMN formulas (containing arginine and fish oil)

High-protein ONS (2-3x a day, minimum of $18 \mathrm{~g}$ protein/dose)

7. We recommend that for patients who are screened as being at nutritional risk before major surgery, where oral nutrition supplementation via ONS is not possible, that a dietician be consulted and an enteral feeding tube be placed and home EN initiated for a period of at least $7 \mathrm{~d}$.

8. If neither oral nutrition supplementation via ONS nor EN is possible, or when protein/kcal requirement ( $>50 \%$ of recommended intake) cannot be adequately met by ONS/EN, we recommend preoperative PN to improve outcomes

9. Preoperative IMN should be considered for all patients undergoing elective major abdominal surgery.

10. We recommend preoperative fasting from midnight be abandoned.

11. In patients undergoing surgery who are considered to have minimal specific risk of aspiration, we encourage unrestricted access to solids for up to $8 \mathrm{~h}$ before anesthesia and clear fluids for oral intake up to $2 \mathrm{~h}$ before the induction of anesthesia.

12. We recommend a preoperative carbohydrate drink containing at least $45 \mathrm{~g}$ of carbohydrate to improve insulin sensitivity (except in type diabetics due to their insulin deficiency state). We suggest that complex carbohydrate (eg, maltodextrin) be used when available.

\section{After Surgery}

1. We recommend that a high-protein diet (via diet or high-protein ONS) be initiated on the day of surgery in most cases, with exception of patients without bowel in continuity, with bowel ischemia, or persistent bowel obstruction. Traditional "clear liquid" and "full liquid" diets should not be routinely used.

2. We recommend reaching an overall protein intake goal is more important than total calorie intake in the postoperative period.

3. We recommend standardized protocols for postoperative nutrition support be instituted.

4. IMN should be considered in all postoperative major abdominal surgical patients for at least $7 \mathrm{~d}$.

5. In patients who meet criteria for malnutrition, who are not anticipated to meet nutritional goals ( $>50 \%$ of protein/kcal) through oral intake, we recommend early EN or tube feeding within $24 \mathrm{~h}$. Where goals are not met through EN, we recommend early PN, in combination with EN if possible.

6. We recommend when using gastric residual volume's as a marker of feeding tolerance, a cutoff of $>500 \mathrm{~mL}$ should be used before tube feeds being suspended or tube feed/EN rate reduced.

7. In patients started on EN and/or PN, we recommend continuation of EN or PN support for patients who are not able to take in at least $60 \%$ of their protein/kcal requirements via the oral route.

8. We recommend posthospital high-protein ONS in all patients after major surgery to meet both calorie and protein needs, especially in the previously malnourished, elderly and sarcopenic patient.

Abbreviations: BMI, body mass index; CT, computed tomography; EN, enteral nutrition; IMN, immunonutrition; ONS, oral nutritional supplement; PONS, perioperative nutrition screen; PN, parenteral nutrition.

supplementation via oral nutritional supplement (ONS) is not possible, a dietician should be consulted and an enteral feeding tube be placed and home enteral nutrition (EN) initiated for a period of at least 7 days. If neither oral nutrition supplementation via ONS nor EN is possible or when protein $/ \mathrm{kcal}$ requirement ( $>50 \%$ of recommended intake) cannot be adequately met by ONS/EN, we recommend preoperative parenteral nutrition $(\mathrm{PN})$ to improve outcomes.

These recommendations are consistent with existing nutrition societal guidelines from the European Society for Parenteral and Enteral Nutrition guidelines indicating severely malnourished patients be supplemented via nutritional therapy before elective surgery. ${ }^{1}$ The duration of preoperative support needed varies in published guidelines from 7 to 14 days. ${ }^{1,21}$ However, even 5-7 days of preoperative nutrition therapy can lead to a $50 \%$ reduction in postoperative morbidity in malnourished patients. ${ }^{49}$ The optimal amount of time preoperative nutrition needed for malnourished patients and an objective measure of nutritional optimization need further study. Intriguingly, recent consensus recommendations from the recent North American Surgical Nutrition Summit suggested that "preventive" preoperative nutrition therapy and optimization involving "metabolic preparation" occur in all patients at risk of undernutrition, rather than simply just correcting deficiencies in severely undernourished patients. ${ }^{50}$ This recommendation is based on the concept that preoperative nutritional care should be introduced early for malnourished and nonmalnourished patients to maintain optimal nutritional status throughout the entire perioperative period. ${ }^{50}$ Further, Kuppinger et al ${ }^{51}$ showed that for patients undergoing abdominal surgery, lower food intake before hospital admission was an independent risk factor for postoperative complications. It is possible in patients found to be malnourished as judged by PONS score components, such as $>10 \%$ weight loss in past 3 months or reduced oral intake $(<50 \%)$ in past 7 days, that surgery should consider being delayed until a reasonable period of compliance with 


\section{POQI Nutrition Six}

\section{Pre-op/Post-op Nutrition Screening Essential \\ 2. Protein more important than calories \\ 3. Stop feeding late pre-op, restart early post-op \\ 4. Consider Oral Nutrition Supplements for All \\ 5. Oral before enteral before parenteral \\ 6. Nutrition management is a team game}

Figure 2. Summary of key recommendations for perioperative nutrition care. POQI indicates Perioperative Quality Initiative.

preoperative nutrition therapy can be achieved. Although the optimal time period for preoperative optimization is yet to be determined, it is likely that at least 2 weeks (and perhaps 4 weeks or more) may be a reasonable timeframe as discussed in the high-risk nutrition pathway below. The risk of delaying surgery versus operating on a patient with known malnutrition must be carefully considered.

Nutrition Pathway in Low Nutrition Risk Perioperative Patients (ie, PONS <1 and Albumin [ALB] >3.0). Patients should be encouraged to take in healthy high-protein (with high-quality protein sources, such as eggs, fish, and lean meats/dairy) complex carbohydrate-rich diets preoperatively (Figure 4A). However, many patients will not be able to meet optimal suggested perioperative energy goals of $25 \mathrm{kcal} / \mathrm{kg} / \mathrm{d}$ and $1.5-2 \mathrm{~g} / \mathrm{kg} / \mathrm{d}$ of protein $(\sim 1 \mathrm{~g} /$ pound of ideal/adjusted body weight) from routine food intake., ${ }^{1,52}$ Thus, we encourage patients to take high-protein ONSs or IMN during the perioperative period unrelated to nutritional status.

Nutrition Pathway in Patients Found to Be at Nutrition Risk (ie, $P O N S>1$ or $A L B<3.0$ ). In patients found to be at nutrition risk, we recommend high-protein ONS or IMN be given before surgery (Figure 4B). This should have a goal of delivering at least $1.2 \mathrm{~g} / \mathrm{kg} / \mathrm{d}$ total of protein. It is the consensus of the group that high-protein ONS should contain $>18 \mathrm{~g} /$ protein/serving in a balanced formula. A reasonable goal for most patients is 3 high-protein ONS servings per day. Previous data utilizing preoperative ONS demonstrated benefits on reduction of surgical-site infections in selected weight-losing patients. ${ }^{53}$ Again, because many patients do not meet their energy needs from normal food, especially malnourished patients, it is the consensus of this consensus group to encourage the use of high-protein ONS or IMN. As patient compliance with ONS intake ( $2-3 \times$ a day) is essential for benefit, it is vital to emphasize the key role of ONS in preoperative therapy. ${ }^{54}$ Further, cost-effectiveness of ONS in hospitalized patients has been shown in a recent large systematic review..$^{55}$

When oral nutrition is unable to meet the protein and calorie requirements in malnourished patients, enteral supplementation should be preferred over PN whenever possible. In 800 patients with gastric cancer undergoing gastrectomy and with severe nutritional risk according to European Society for Parenteral and Enteral Nutrition definitions, the incidence of surgical-site infections was significantly lower in the group receiving adequate energy support via oral, EN, and/or PN for at least 10 days than in the group with inadequate/no support for $<10$ days $(17.0 \%$ vs $45.4 \% ; P=.00069)$. In multivariate analysis, nutritional therapy was an independent factor associated with fewer surgical-site infections (odds ratio, 0.14; 95\% confidence interval [CI], 0.05-0.37; $P=.0002) .{ }^{56}$ Preoperative PN should only be utilized in patients with malnutrition or nutritional risk where energy requirement cannot be adequately met by EN. A period of 7-14 days of PN is recommended. If PN is required to meet energy needs, it should be combined whenever possible with EN or ONS. For surgical patients, the benefits of nutritional therapy have been consistently shown in cases of severe undernutrition ${ }^{57-59}$ and confirmed by meta-analyses and expert consensus review. ${ }^{60,61} \mathrm{PN}$ was found to reduce the rate of postoperative complications in malnourished patients. ${ }^{57-60}$ Patients in these studies were fed preoperatively for at least 7-10 days. The results of the meta-analysis by Braunschweig et $\mathrm{al}^{62}$ also favor PN for malnourished patients. A significantly lower mortality with a tendency toward lower rates of infection was also found in malnourished patients receiving $\mathrm{PN}$ in the meta-analysis by Heyland et al.$^{61}$ In a later systematic review, which focused on patients undergoing GI surgery, preoperative PN statistically significantly reduced the risk for major complications from $45 \%$ to $28 \%$. ${ }^{63}$

With regard to the timing of preoperative $\mathrm{PN}$ use, the benefits of preoperative PN for 7-15 days are most clearly shown in patients with documented malnutrition before major GI surgery. ${ }^{57,58}$ When PN is given for the 10 days preoperatively and continued for 9 days postoperatively, the complication rate is $30 \%$ lower versus no PN control group and there is a reduction in mortality. ${ }^{58}$ It is the opinion of the consensus group that in patients with significant nutritional risk, the potential for increased benefit will justify the preoperative extension of preoperative hospitalization or outpatient PN delivery length to 10-14 days of PN delivery. To avoid refeeding syndrome in severely malnourished patients, PN calorie delivery should be increased in a stepwise fashion (with dietician/pharmacist guidance) and laboratory and cardiac monitoring should be initiated with adequate precautions to replace potassium, magnesium, phosphate, and thiamine. ${ }^{64}$

\section{Minimizing Preoperative Fasting and Role of Preoperative Oral Carbohydrate Loading}

Perioperative fasting can exacerbate surgical stress response, aggravate insulin resistance, exaggerate protein losses, and impair GI function. Additionally, preoperative fasting is associated with a number of patient-centered consequences including thirst, hunger, headaches, and anxiety. It is now known that preoperative overnight fasting is unnecessary in most cases; clear fluids taken up until 2 hours before induction do not increase gastric volumes, therefore they 


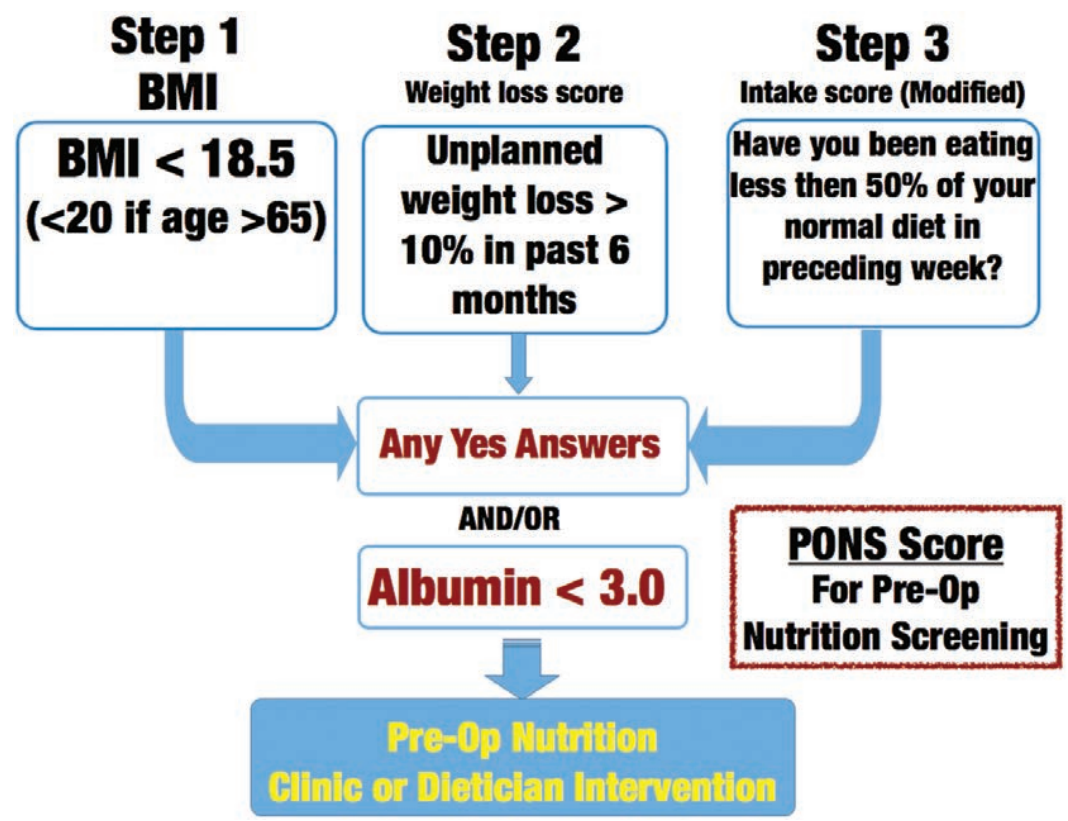

Figure 3. PONS assessment tool. BMI indicates body mass index; PONS, preoperative nutrition score.

pose no risk for aspiration, and in fact have been found to stimulate gastric emptying. ${ }^{50,65}$

Delivery of sufficient exogenous carbohydrate is considered the best method to induce a metabolically fed state preoperatively. Carbohydrate loading is accomplished with the consumption of $50 \mathrm{~g}$ carbohydrates as a clear liquid 2-3 hours preoperatively and in some studies/centers $100 \mathrm{~g}$ the evening before. The use of preoperative carbohydrate-loading strategies has been associated with a statistically significant reduced LOS, especially in major abdominal surgery (mean difference, -1.66 days; $95 \%$ CI, -2.97 to -0.34 ). ${ }^{66}$ For best results, the dose 2-3 hours before surgery should be consumed within 5-10 minutes (not sipped over time) to enhance insulin secretion. The carbohydrate product most often studied contains maltodextrin as source of carbohydrate, and its low osmolality induces faster gastric emptying. Direct comparisons with more simple sugar containing solutions (glucose) are not yet studied. However, there are significant data suggesting the negative impact of high versus low glycemic index meal on response of glucose, insulin, and glucagon. ${ }^{67}$ Overall, based on the low risk of harm, potentially improved nitrogen balance, better insulin sensitivity, and signal of reduced LOS in major abdominal surgery, we recommend the oral intake of carbohydratecontaining solutions preoperatively and suggest solutions containing complex carbohydrates be used when available.

\section{Role of Perioperative IMN}

IMN has been proposed as a risk-reduction strategy in surgical patients for over 25 years. Arginine, omega-3 fatty acid, and antioxidants are delivered in combination at high levels in various EN and ONS formulas. Conditionally essential arginine is rapidly depleted after surgical stress but can be supplemented with IMN. ${ }^{68}$ Arginine is important for activation of $\mathrm{T}$ lymphocytes, promotion of T-helper cells, phagocytosis, and respiratory burst generation. ${ }^{69}$ Arginine serves as a precursor to nitric oxide and proline; both are important to anastomotic and wound healing-nitric oxide promotes vasodilation and tissue oxygenation while proline contributes to collagen deposition during healing. The omega-3 fatty acids docosahexaenoic acid and eicosapentaenoic acid play a wide range of anti-inflammatory roles, reducing oxidative injury, down-regulating arachidonic acid, and generating resolvins. ${ }^{70}$

IMN ingredients, timing, dose, and duration vary from study to study. The clinical effect targeted to the aforementioned pathways appears most profound when the nutrients are used in combination. Most surgical IMN studies have applied either 5 days of preoperative supplementation and/or 7 days of supplementation postoperatively. Studies of single immunonutrients (ie, arginine alone) have not demonstrated the same level of benefit, suggesting synergism of different components and complete nutrition delivery is crucial to IMN efficacy. ${ }^{70}$

Early studies strongly demonstrate that preoperative IMN reduced complications and LOS. ${ }^{71}$ A Cochrane Library analysis reported decreased total and infectious complications with the use of preoperative IMN. ${ }^{63}$ Evidence suggests that patients undergoing high-risk GI surgery were the most likely to benefit, possibly due to the higher perioperative risk of complication. ${ }^{72}$ Due to the large number of small to medium size trials, many conclusions have been drawn from meta-analyses. In their landmark meta-analysis in 2011, Drover et $\mathrm{al}^{73}$ demonstrated a $40 \%$ reduction in perioperative infectious complications with IMN. The effect observed in this analysis was similar whether the IMN was given preoperatively only, pre- and postoperatively, or postoperatively alone. Much has been written on the value of pre- versus postoperative IMN and there may be value to administration both before and after surgery. However, a recent meta-analysis suggested that preoperative only IMN did not improve outcomes when compared to preoperative isonitrogenous ONS.70 Additional meta-analyses have demonstrated that postoperative IMN reduces infectious complications, ${ }^{72,74-77}$ including the recent analysis from Ljungqvist et al. ${ }^{72,74-77}$ One meta-analysis of early enteral postoperative 
A

\section{PRE-OPERATIVE NUTRITION CARE PATHWAY}

\section{Low Nutrition Risk}

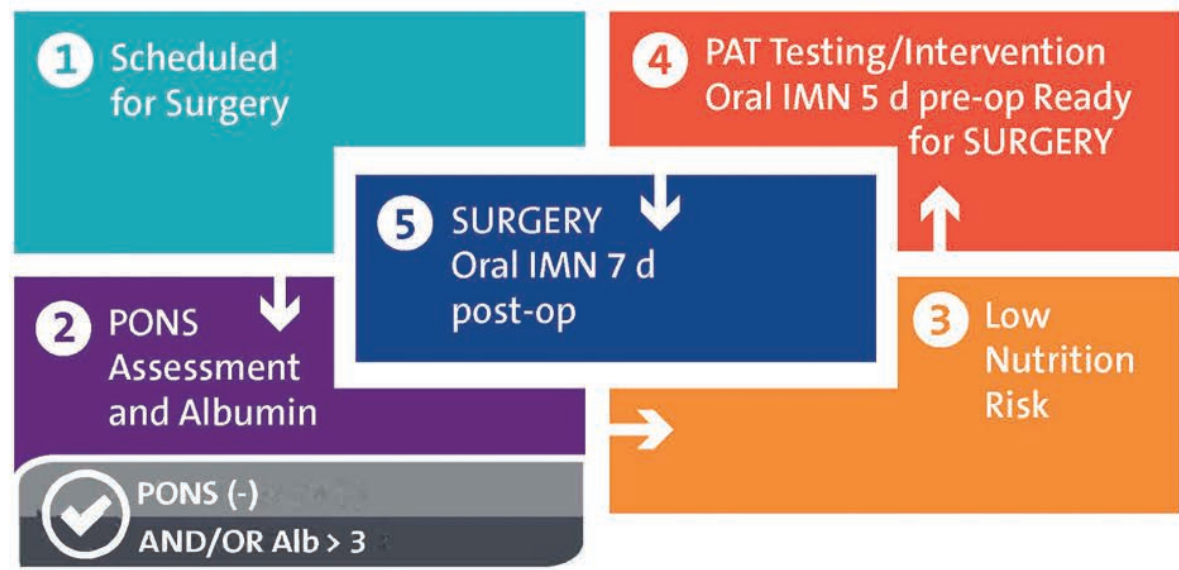

B

\section{PRE-OPERATIVE NUTRITION CARE PATHWAY High Nutrition Risk}

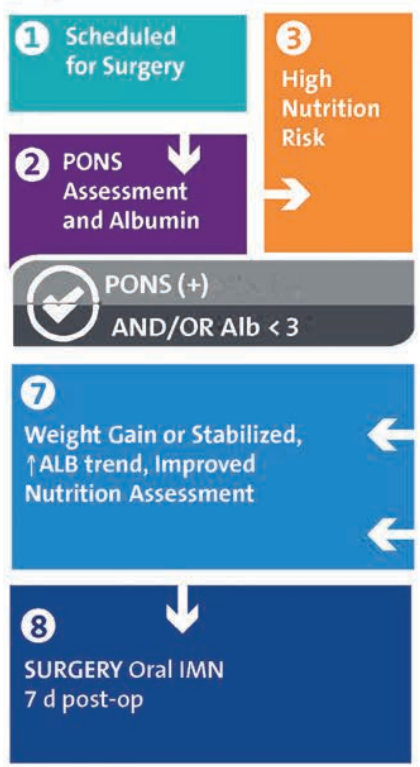

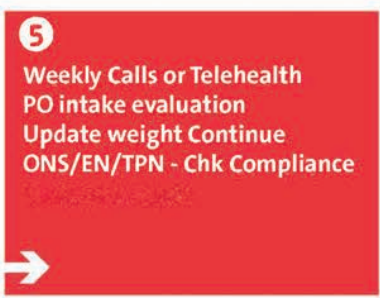

6 1 Month Visit/Reassessment Alb check/Weight check Continue ONS/EN/TPN- Ready for Surgery?

\section{7}

Weekly Calls/Continue Nutrition Therapy Reassess Weekly/Consider Surgery Delay Continue ONS/EN/TPN - Chk Compliance Consider other weight loss etiologies

(i.e. $\uparrow$ tumor burden/infection) Communicate w/Primary Surgeon

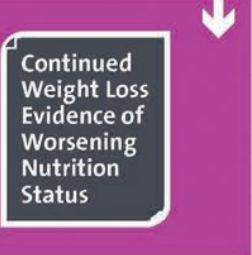

IMN also demonstrated a reduction in anastomotic leaks. ${ }^{78}$ Limitations of these data include many early IMN studies informing that these meta-analyses were not balanced with an isocaloric, isonitrogenous controls. Further, some later small randomized trials of IMN did not show benefit compared to isonitrogenous formulas..$^{79-81}$

Two studies of perioperative IMN have occurred in the context of ERP and have suggested benefit. The larger was a RCT of 264 patients that demonstrated a reduction in infectious complications $(23.8 \%$ vs $10.7 \% ; P=.0007)$, particularly wound infections $(16.4 \%$ vs $5.7 \% ; P=.0008)$ with the use of IMN when compared to standard high-calorie supplements. ${ }^{82}$ In a separate study of IMN compared to dietary advice without supplementation by the same authors, wound infection rates in laparoscopic colectomy were significantly reduced with the use of IMN $(11.5 \%$ vs $0 \% ; P=.006){ }^{83}$
Figure 4. Example of preoperative nutritional care pathways. A, Nutrition pathway for low nutrition risk patients. B, Nutrition pathway for high nutrition risk patients, as defined by any positive response on the PONS score (currently utilized by Duke University Peri-Operative Optimization Team [POET] Nutrition Clinic). Alb indicates Albumin; IMN, immunonutrition; PAT, pre-anesthesia testing clinic; POET, perioperative enhancement team; PONS, preoperative nutrition score.
A major real-world quality improvement effort using preoperative IMN in 3375 patients in Washington state demonstrated a reduction of $23 \%$ in the number of patients with a prolonged $\operatorname{LOS}(P=.05)$ in a covariate-matched analysis. ${ }^{84}$

The POQI-2 group was divided regarding the strength of their recommendation for IMN. Expert opinions based on interpretation of the evidence ranged from "recommend" to "suggest" and the finally agreed-upon consensus statement to "consider" IMN. Overall there were many concerns about the quality of the overall evidence, including the age of many seminal IMN studies published in the early 2000 s. There was also concern that older studies were not controlled with isocaloric, isonitrogenous formulas. ${ }^{85}$ Overall, IMN study sample sizes are smaller, although a number of medium size trials ( $n=\sim 200-300$ ) are published. Concerns were raised regarding the level of industry sponsorship 
in the literature and the potential biases these can carry. Without question, additional definitive clinical trials comparing IMN to high-protein ONS in the preoperative setting and preoperative IMN alone versus pre- and postoperative IMN versus postoperative IMN alone are needed.

\section{Postoperative Nutrition}

Early resumption of oral intake after surgery is now clearly realized to be safe ${ }^{86}$ and vital for optimizing postoperative outcomes. Early oral feeding immediately after major surgery, including GI surgery, is associated with a decrease in postoperative complications, LOS, and costs. ${ }^{87,88}$ In fact, multiple meta-analyses now report that feeding within 24 hours after GI surgery decreases mortality as well as major morbidities. ${ }^{15,16,89}$ Specifically, a systematic review and meta-analysis of the effects of early enteral feeding within 24 hours of intestinal surgery (versus no feeding within 24 hours) demonstrated a significant reduction in mortality (relative risk [RR], 0.42 [95\% CI, 0.18-0.96]) and no benefit or harm related to anastomotic dehiscence (RR, $0.62[95 \%$ CI, 0.3-1.28]) in the early fed group. ${ }^{89}$ Overall, early postoperative feeding versus traditional withholding of feeding until return of bowel function was not found to contribute to anastomotic breakdown or increase risk of nausea after surgery.

As earlier stated, anabolism cannot be achieved in the postoperative period when glucose is administered alone without adequate protein delivery. ${ }^{90}$ Unfortunately, to this point, provision of calories alone has continued to be focused on in surgical nutrition messages. ${ }^{90}$ It is well known that inadequate protein intake is associated with loss of lean body mass, which impairs functional recovery and physical quality of life. Provision of protein, independent of whether energy or total calorie requirements are met, can maintain lean muscle mass and reduce the risk of subsequent frailty in the elderly. ${ }^{91,92}$ Finally, a key high-impact recent trial conducted in colorectal surgery patients within an enhanced recovery after surgery/ERP pathway demonstrated in patients receiving high-protein ONS postoperatively that consumption of $>60 \%$ of protein needs over the first 3 postoperative days was associated with a 4.4-day reduction in $\operatorname{LOS}(P<.001) .{ }^{93}$

Thus, the group was in full consensus recommending that a high-protein diet (via diet or high-protein ONS) be initiated on the day of surgery in most cases, with the exception of patients with bowel not in continuity, bowel ischemia, or persistent bowel obstruction. Traditional "clear liquid" and "full liquid" diets should not be routinely used as they typically do not provide adequate nutrition or protein delivery. Further, the group emphasized that reaching the overall protein intake goal is more important than total calorie intake in the postoperative period.

Role of High-Protein ONS, EN, and PN in the Postoperative Period. The type of nutrition support delivered in the postoperative setting is primarily determined by the patient's ability to achieve calorie (25-30 kcal/ $\mathrm{kg} / \mathrm{d}$ ) and protein $(1.5-2 \mathrm{~g} / \mathrm{kg} / \mathrm{d})$ goals and tolerance of oral intake. ${ }^{1,21,22,90}$ A practical approach derived from recent publications $s^{1,21,22,90,94}$ indicates that patients tolerating $50 \%-$ $100 \%$ of nutrition goals should receive high-protein ONS
(2-3× a day) to meet protein needs. In patients consuming $<50 \%$ via the oral route, EN via tube feeds should be given. PN should be utilized if $>50 \%$ of protein/calories needs are not met via oral/EN for $>7$ days, even in well-nourished patients.

When oral nutrition is not tolerated or feasible, EN under guidance of a dietician should be initiated. Early EN within 24 hours of surgery versus later feeding has been clearly shown to reduce morbidity and mortality in 2 metaanalyses (1 Cochrane systematic review). ${ }^{86,89}$ Another metaanalysis comparing EN within 24 hours of GI surgery with traditional postoperative management demonstrated a $45 \%$ decrease in risk of overall postoperative complications. No differences in the incidence of anastomotic dehiscence were observed..$^{15}$ Thus, in patients who meet criteria for malnutrition and who are not anticipated to meet nutritional goals ( $>50 \%$ of protein $/ \mathrm{kcal}$ ) through oral intake, we recommend early EN or tube feeding within 24 hours. Further, in patients started on EN and/or PN, we recommend continuation of EN or PN support for patients who are not able to take in at least $60 \%$ of their protein/kcal requirements via the oral route. Finally, based on recent randomized clinical trial data and new clinical guidelines, ${ }^{22}$ we recommend that when using gastric residual volumes as a marker of feeding tolerance, a cutoff of $>500 \mathrm{~mL}$ should be used before tube feeds are suspended or tube feed/EN rate reduced. Ideally, postoperative nutrition should continue for a minimum period of 4 weeks in malnourished patients (and perhaps longer depending on size of surgery and extent of malnutrition at presentation) and perhaps longer as described in the Role of Nutrition in Optimizing Recovery From Surgery Posthospital Discharge section below.

Role of PN in the Postoperative Period. In patients at risk for malnutrition (PONS $>1$ or ALB <3.0) where nutrition goals are not met via EN, we recommend early $\mathrm{PN}$, in combination with EN if possible. This is based on data from metaanalysis incorporating 27 studies in a meta-analysis of PN in surgical patients. These data showed a lower complication rate in patients receiving $\mathrm{PN}$, especially in patients found at risk for malnutrition. ${ }^{61}$ An influence of $\mathrm{PN}$ on the mortality of surgical patients was not shown. Further, a meta-analysis by Braunschweig et $\mathrm{al}^{62}$ showed that in malnourished patients, PN use resulted in a significantly lower mortality with a tendency toward lower rates of infection. Traditionally, concerns for infection risk have limited the use of PN to achieve optimal nutrition delivery. However, 3 recent large randomized trials of $\mathrm{PN}$ in critical illness ${ }^{95-97}$ (including a recent New England Journal of Medicine publication $^{96}$ ) have clearly demonstrated that PN administration is no longer associated with any increased risk of infection.

Further, one of the recent large-scale multicenter studies investigated whether PN should be supplemented "early" (within 4 days) or "late" (after 7 days) in the event of impaired enteral tolerance. ${ }^{97}$ Late infections (postday 9) were reduced in the PN group versus EN alone. The results provide arguments to initiate PN in malnourished patients and the acutely ill on day 4 at the latest. ${ }^{98}$ Overall, as stated recently by Awad and Lobo, " ${ }^{6}$ there is grade A evidence for use of PN in undernourished patients in whom EN is not feasible nor tolerated, and in patients with postoperative complications impairing 
GI function."1 This contributed to our recommendation to initiate early $\mathrm{PN}$ in patients at risk for malnutrition when goals are not met early via EN. Further, we recommend continuation of PN support for patients not able to take in at least $60 \%$ of their protein $/ \mathrm{kcal}$ requirements via the oral route. Finally, given the new availability of fish oil containing lipid formulations in the United States, there are data supporting a benefit of utilizing fish oil containing balanced lipid formulations versus soy lipid alone in patients requiring postoperative total parenteral nutrition. These data from a recent systematic analysis in 23 RCTs, including 1502 surgical and intensive care unit (ICU) patients, demonstrated that fish oil containing lipids reduced LOS and infectious complications versus traditional soy-only lipids. ${ }^{99}$

\section{Role of Nutrition in Optimizing Recovery From Surgery Posthospital Discharge}

Even with initiation of preoperative nutritional support, patients who develop postoperative complications will continue to lose weight and are at risk for serious further deterioration of nutritional status as was recently shown by Grass et al. ${ }^{100}$ These patients identified via preoperative nutritional screening clearly require continuing nutritional follow-up postdischarge. Further in a considerable number of patients after major GI surgery, oral calorie intake will be inadequate for a prolonged period with a significant risk for postoperative malnutrition, especially after discharge. In patients after ICU discharge, an observational study demonstrated an average spontaneous calorie intake of $700 \mathrm{kcal} / \mathrm{d}$. This is far insufficient in the anabolic phase of rehabilitation when a caloric intake of 1.2-1.5x resting energy expenditure is recommended and thought to be required. ${ }^{101}$ It also emphasizes the importance of closely observing food intake in postoperative patients. In patients who have lost significant weight after surgery/illness, a considerable period of significant increases in calorie and protein delivery is required for recovery. ${ }^{102}$ As stated by Ansel Keys, principal investigator of the legendary Minnesota Starvation Experiment after World War II,

Enough food must be supplied to allow tissues destroyed during starvation to be rebuilt ... our experiments show in an adult no appreciable rehabilitation can take place on diet of 2000 calories/day. The proper level is more like $4000 \mathrm{kcal}$ daily for some months. ${ }^{103}$

In this study of healthy, young men who sustained weight loss due to inadequate food intake (without the catabolic/ hypermetabolic effects of a surgical insult), recovery to a normal weight took an average of $4000 \mathrm{kcal} / \mathrm{d}$ for an average of 6 months to 2 years. Hence, the posthospital discharge period after major surgery is an essential period where nutrition support is required to optimize outcomes.

Thus, we must ask ourselves if our postoperative patients will be able to consume adequate protein and calories to optimally recover. As stated, data and experience have taught us in most cases the answer is no. Recovering postoperative patients, especially elderly individuals, are challenged by decreased appetites, persistent nausea, constipation from opiates, and lack of education about how to optimize their diet. ${ }^{104}$ To address this, a large body of data demonstrates that high-protein ONS should be a fundamental part of our postoperative discharge care plan. Meta-analysis data in a range of hospitalized patients, including surgery patients, demonstrate that ONS reduces mortality, reduces hospital complications, reduces hospital readmissions, shortens LOS, and reduces hospital costs..$^{55,105-107}$ A large hospital database analysis of ONS use in 724,000 patients matched with controls not receiving ONS showed a $21 \%$ reduction in hospital LOS and for every \$1 (United States) spent on ONS, \$52.63 was saved in hospital costs. ${ }^{20}$ Finally, a very recent large randomized trial of 652 patients in 78 centers studied the effect of high-protein ONS with $\beta$-hydroxy $\beta$-methylbutyrate versus placebo ONS in elderly hospitalized patients at risk for malnutrition. ${ }^{108}$ Results demonstrated that high-protein ONS with $\beta$-hydroxy $\beta$-methylbutyrate reduced 90-day mortality by $\sim 50 \%$ relative to placebo $(4.8 \%$ vs $9.7 \%$; RR, $0.49 ; 95 \% \mathrm{CI}$, $0.27-0.90 ; P=.018) .{ }^{108}$ As such, we suggest $4-8$ weeks minimum of postoperative HP-ONS in all patients having major surgery, and as long as 3-6 months postoperatively in more severely malnourished patients or those with prolonged postoperative or ICU stays. Further research focused on highrisk postoperative patients is needed in this critical period of recovery.

For future research questions, please see Supplemental Digital Content, Appendix 4, http://links.lww.com/AA/ C160, for a full discussion. 1

\section{APPENDIX}

The members of the Perioperative Quality Initiative (POQI) 2 workgroup and POQI chairs are as follows: Tong Joo Gan, MD, MHS, FRCA, Professor and Chairman, Department of Anesthesiology, Stony Brook University School of Medicine; Andrew D. Shaw, MB, FRCA, FCCM, FFICM, Professor of Anesthesiology, Vanderbilt University School of Medicine, Executive Vice Chair, Department of Anesthesiology, Vanderbilt University Medical Center; Julie K. M. Thacker, MD, Assistant Professor of Surgery, Medical Director, Enhanced Recovery Program, Department of Surgery, Division of Advanced Oncologic and Gastrointestinal Surgery, Duke University Medical Center; Timothy E. Miller, MB ChB, FRCA, Associate Professor of Anesthesiology, Chief, Division of General, Vascular and Transplant Anesthesia, Duke University Medical Center; Postoperative Gastrointestinal Dysfunction (POGD) group: Traci L. Hedrick, MD, MS, Assistant Professor of Surgery, Co-Director Enhanced Recovery Program, Department of Surgery, University of Virginia Health System; Matthew D. McEvoy, MD, Associate Professor of Anesthesiology, Vanderbilt University School of Medicine, Vice Chair for Educational Affairs, Department of Anesthesiology, Vanderbilt University Medical Center, Michael (Monty) G. Mythen, MBBS, MD, FRCA, FFICM, FCAI (Hon), Smiths Medical Professor of Anesthesia, University College London/University College London Hospital National Institute of Health Research Biomedical Research Centre, London, United Kingdom; Roberto Bergamaschi, MD, PhD, Professor of Surgery, Division of Colon and Rectal Surgery, State University of New York, Stony Brook, NY; Ruchir Gupta, MD, Assistant Professor of Anesthesiology, Stony Brook School of Medicine, Health Science Center, Stony Brook, NY; Stefan D. Holubar, MD, MS, Director, Dartmouth Enhanced Recovery Program, DartmouthHitchcock Medical Center, Geisel School of Medicine at Dartmouth, The Dartmouth Institute for Health Policy and Clinical Practice; Anthony J. Senagore, MD, MS, MBA, Professor and Vice Chair for Clinical Operations, Chief, Gastrointestinal and Oncologic Surgery, Co-Director Department of Surgery Clinical Outcomes Research Program, University of Texas Medical Branch. Nutrition Group: Paul E. Wischmeyer, MD, EDIC, Professor of Anesthesiology and Surgery, Director of Perioperative Research, Duke Clinical Research Institute, Director, Nutrition Support Service, Duke University Hospital, Duke University School of Medicine, Durham, NC; Franco Carli, MD, MPhil, Professor of Anesthesia, McGill University, Montreal, Quebec, Canada; David C. Evans, MD, FACS, Associate Professor of Surgery, Medical Director, Level 1 Trauma Center and Nutrition Support Service, Department of Surgery, Division of Trauma, Critical Care, and Burn, Columbus, OH; Sarah Guilbert, RD, LDN, 
CNSC, Clinical Dietitian Duke Nutrition Support Team/Perioperative Nutrition (POET) Clinic, Duke University Hospital, Durham, NC; Rosemary Kozar, MD, PhD, Director of Research, Shock Trauma, Associate Director of Shock Trauma Anesthesia Research Center, Professor of Surgery, University of Maryland School of Medicine, Baltimore, MD; Aurora Pryor, MD, FACS, Professor of Surgery, Chief Bariatric, Foregut and Advanced Gastrointestinal Surgery, Department of Surgery, Stony Brook Medicine, Stony Brook, NY; Robert H. Thiele, MD, Assistant Professor, Departments of Anesthesiology and Biomedical Engineering, Divisions of Cardiac, Thoracic, and Critical Care Anesthesiology, Co-Director, University of Virginia Enhanced Recovery After Surgery Program, University of Virginia School of Medicine, Charlottesville, VA; Sotiria Everett, EdD, RD, Clinical Assistant Professor, Nutrition Division, Department of Family, Population, Preventive Medicine, Stony Brook Medicine, Stony Brook, NY; Mike Grocott, Respiratory and Critical Care Research Area, National Institute for Health Research Biomedical Research Centre, University Hospital Southampton, National Health Service Foundation Trust, Southampton, UK and Integrative Physiology and Critical IIIness Group, Clinical and Experimental Sciences, Faculty of Medicine, University of Southampton, Southampton, United Kingdom. PRO Group: Ramon E. Abola, MD, Department of Anesthesiology, Stony Brook Medicine, Stony Brook, NY; Elliott Bennett-Guerrero, MD, Department of Anesthesiology, Stony Brook Medicine, Stony Brook, NY; Michael L. Kent, MD, Department of Anesthesiology, Walter Reed National Military Medical Center, Bethesda, MD; Liane S. Feldman, MD, Department of Surgery, Steinberg-Bernstein Centre for Minimally Invasive Surgery and Innovation, McGill University Health Centre, Montreal, Quebec, Canada; Julio F. Fiore Jr, PhD, Department of Surgery, Steinberg-Bernstein Centre for Minimally Invasive Surgery and Innovation, McGill University Health Centre, Montreal, Quebec, Canada.

\section{ACKNOWLEDGMENTS}

The authors thank Jonathon Cook and the Duke Clinical Research Institute Communications group for assistance with graphic design of figures in this article.

\section{DISCLOSURES}

Name: Paul E. Wischmeyer, MD, EDIC.

Contribution: This author helped with primary drafting and writing of the manuscript, creation of figures, manuscript editing, and revisions at all stages of preparation and submission.

Conflicts of Interest: P. E. Wischmeyer was the associate editor of Clinical Nutrition (Elsevier) and was the chair of the Perioperative Quality Initiative (POQI) nutrition group. He received grant funding related to Improving Nutrition Delivery in Acute Illness from the National Institute of Health National Heart, Lung, and Blood Institute R34 HL109369, Canadian Institutes of Health Research, Baxter, Fresenius, Lyric Pharmaceuticals, Isomark Inc, and Medtronics. He served as a consultant on Improving Nutrition Care in Intensive Care Unit (ICU) and Perioperative Medicine to Nestle, Abbott, Fresenius, Baxter, Medtronics, Nutricia, and Lyric Pharmaceuticals, and Takeda for research related to this work. He received honoraria or travel expenses for lectures on improving nutrition care in illness from Abbott, Fresenius, and Medtronics.

Name: Franco Carli, MD, MPhil.

Contribution: This author helped write, review, and edit the manuscript.

Conflicts of Interest: F. Carli was a member of the POQI nutrition group.

Name: David C. Evans, MD, FACS.

Contribution: This author helped write, review, and edit the manuscript.

Conflicts of Interest: D. C. Evans was a member of the POQI nutrition group.

Name: Sarah Guilbert, RD, LDN, CNSC.

Contribution: This author helped write, review, and edit the manuscript.

Conflicts of Interest: S. Guilbert was a member of the POQI nutrition group.

Name: Rosemary Kozar, MD, PhD.

Contribution: This author helped write, review, and edit the manuscript.
Conflicts of Interest: R. Kozar was a member of the POQI nutrition group.

Name: Aurora Pryor, MD, FACS

Contribution: This author helped write, review, and edit the manuscript.

Conflicts of Interest: A. Pryor was a member of the POQI nutrition group.

Name: Robert H. Thiele, MD.

Contribution: This author helped write, review, and edit the manuscript.

Conflicts of Interest: R. H. Thiele was a member of the POQI nutrition group.

Name: Sotiria Everett, EdD, RD

Contribution: This author helped write, review, and edit the manuscript.

Conflicts of Interest: S. Everett was a member of the POQI nutrition group.

Name: Mike Grocott, BSc, MBBS, MD, FRCA, FRCP, FFICM.

Contribution: This author helped write, review, and edit the manuscript.

Conflicts of Interest: M. Grocott was a member of the POQI nutrition group.

Name: Tong J. Gan, MD, MHS, FRCA

Contribution: This author helped write, review, edit, and revise the manuscript.

Conflicts of Interest: T. J. Gan served as a POQI Conference Organizer and received honoraria from Edwards, Mallinckrodt, Merck, Medtronic, and Pacira.

Name: Andrew D. Shaw, MB, FRCA, FCCM, FFICM.

Contribution: This author helped write, review, edit, and revise the manuscript.

Conflicts of Interest: A. D. Shaw was a consultant for Astute Medical, FAST BioMedical, and Edwards Lifesciences, and was the Data Safety Monitoring Board chair for the STOP-AKI clinical trial. He served as a POQI Conference Organizer.

Name: Julie K. M. Thacker, MD.

Contribution: This author helped write, review, edit, and revise the manuscript.

Conflicts of Interest: J. K. M. Thacker was on the Speaker's Bureau and received consulting fees from Pacira, Edwards, Covidien, Medtronic, and Merck. She served as a POQI Conference Organizer. Name: Timothy E. Miller, MB, ChB, FRCA.

Contribution: This author helped write, review, edit, submit, and revise the manuscript.

Conflicts of Interest: T. E. Miller served as a POQI Conference Organizer and received honoraria from Edwards Lifesciences and Cheetah Medical.

This manuscript was handled by: Thomas R. Vetter, MD, MPH.

\section{REFERENCES}

1. Braga M, Ljungqvist $\mathrm{O}$, Soeters $\mathrm{P}$, Fearon $\mathrm{K}$, Weimann A, Bozzetti F; ESPEN. ESPEN guidelines on parenteral nutrition: surgery. Clin Nutr. 2009;28:378-386.

2. Correia MI, Waitzberg DL. The impact of malnutrition on morbidity, mortality, length of hospital stay and costs evaluated through a multivariate model analysis. Clin Nutr. 2003;22:235-239.

3. Bozzetti F, Gianotti L, Braga M, Di Carlo V, Mariani L. Postoperative complications in gastrointestinal cancer patients: the joint role of the nutritional status and the nutritional support. Clin Nutr. 2007;26:698-709.

4. Kassin MT, Owen RM, Perez SD, et al. Risk factors for 30-day hospital readmission among general surgery patients. J Am Coll Surg. 2012;215:322-330.

5. Thomas MN, Kufeldt J, Kisser U, et al. Effects of malnutrition on complication rates, length of hospital stay, and revenue in elective surgical patients in the G-DRG-system. Nutrition. 2016;32:249-254.

6. Awad S, Lobo DN. What's new in perioperative nutritional support? Curr Opin Anaesthesiol. 2011;24:339-348.

7. Geurden B, Franck E, Weyler J, Ysebaert D. The risk of malnutrition in community-living elderly on admission to hospital for major surgery. Acta Chir Belg. 2015;115:341-347. 
8. Gillis C, Nguyen TH, Liberman AS, Carli F. Nutrition adequacy in enhanced recovery after surgery: a single academic center experience. Nutr Clin Pract. 2015;30:414-419.

9. Malietzis G, Currie AC, Athanasiou T, et al. Influence of body composition profile on outcomes following colorectal cancer surgery. Br J Surg. 2016;103:572-580.

10. Vaid S, Bell T, Grim R, Ahuja V. Predicting risk of death in general surgery patients on the basis of preoperative variables using American College of Surgeons National Surgical Quality Improvement Program data. Perm J. 2012;16:10-17.

11. Drover JW, Cahill NE, Kutsogiannis J, et al. Nutrition therapy for the critically ill surgical patient: we need to do better! JPEN J Parenter Enteral Nutr. 2010;34:644-652.

12. Stratton RJ, Elia M. Who benefits from nutritional support: what is the evidence? Eur J Gastroenterol Hepatol. 2007;19:353-358.

13. Benoist $S$, Brouquet A. Nutritional assessment and screening for malnutrition. J Visc Surg. 2015;152(suppl 1):S3-S7.

14. El Nakeeb A, Fikry A, El Metwally T, et al. Early oral feeding in patients undergoing elective colonic anastomosis. Int J Surg. 2009;7:206-209.

15. Osland E, Yunus RM, Khan S, Memon MA. Early versus traditional postoperative feeding in patients undergoing resectional gastrointestinal surgery: a meta-analysis. JPEN J Parenter Enteral Nutr. 2011;35:473-487.

16. Lewis SJ, Egger M, Sylvester PA, Thomas S. Early enteral feeding versus "nil by mouth" after gastrointestinal surgery: systematic review and meta-analysis of controlled trials. BMJ (Clinical Research Ed). 2001;323:773-776.

17. Vlug MS, Bartels SA, Wind J, Ubbink DT, Hollmann MW, Bemelman WA; Collaborative LAFA Study Group. Which fast track elements predict early recovery after colon cancer surgery? Colorectal Dis. 2012;14:1001-1008.

18. Gustafsson UO, Oppelstrup H, Thorell A, Nygren J, Ljungqvist O. Adherence to the ERAS protocol is associated with 5-year survival after colorectal cancer surgery: a retrospective cohort study. World J Surg. 2016;40:1741-1747.

19. Williams JD, Wischmeyer PE. Assessment of perioperative nutrition practices and attitudes-A national survey of colorectal and GI surgical oncology programs. Am J Surg. 2017;213:1010-1018.

20. Philipson TJ, Snider JT, Lakdawalla DN, Stryckman B, Goldman DP. Impact of oral nutritional supplementation on hospital outcomes. Am J Manag Care. 2013;19:121-128.

21. Weimann A, Braga M, Harsanyi L, et al; DGEM (German Society for Nutritional Medicine); ESPEN (European Society for Parenteral and Enteral Nutrition). ESPEN guidelines on enteral nutrition: surgery including organ transplantation. Clin Nutr. 2006;25:224-244.

22. McClave SA, Taylor BE, Martindale RG, et al; Society of Critical Care Medicine; American Society for Parenteral and Enteral Nutrition. Guidelines for the provision and assessment of nutrition support therapy in the adult critically ill patient: Society of Critical Care Medicine (SCCM) and American Society for Parenteral and Enteral Nutrition (A.S.P.E.N.). JPEN J Parenter Enteral Nutr. 2016;40:159-211.

23. Arends J, Bachmann P, Baracos V, et al. ESPEN guidelines on nutrition in cancer patients. Clin Nutr. 2017;36:11-48.

24. Weimann A, Braga M, Carli F, et al. ESPEN guideline: clinical nutrition in surgery. Clin Nutr. 2017;36:623-650.

25. Miller TE, Shaw AD, Mythen MG, Gan TJ. Perioperative quality initiative IW. Evidence-based perioperative medicine comes of age: the perioperative quality initiative (POQI): the 1st consensus conference of the perioperative quality initiative (POQI). Perioper Med (Lond). 2016;5:26.

26. Millan IS, Hill J, Wischmeyer P. Measurement of skeletal muscle glycogen status in critically ill patients: a new approach in critical care monitoring. Crit Care. 2015;19(suppl 1):P400-P400.

27. Thiele RH, Raghunathan K, Brudney CS, et al; Perioperative Quality Initiative (POQI) I Workgroup. American Society for Enhanced Recovery (ASER) and Perioperative Quality Initiative (POQI) joint consensus statement on perioperative fluid management within an enhanced recovery pathway for colorectal surgery. Perioper Med (Lond). 2016;5:24.
28. Elia M. The MUST Report: Nutritional Screening for Adults: A Multidisciplinary Responsibility. Maidenhead, Berks, United Kingdom: BAPEN; 2003.

29. Bohl DD, Shen MR, Kayupov E, Della Valle CJ. Hypoalbuminemia independently predicts surgical site infection, pneumonia, length of stay, and readmission after total joint arthroplasty. J Arthroplasty. 2016;31:15-21.

30. Jiang N, Deng JY, Ding XW, et al. Prognostic nutritional index predicts postoperative complications and long-term outcomes of gastric cancer. World J Gastroenterol. 2014;20:10537-10544.

31. Baker JP, Detsky AS, Wesson DE, et al. Nutritional assessment: a comparison of clinical judgement and objective measurements. N Engl J Med. 1982;306:969-972.

32. Kruizenga HM, Seidell JC, de Vet HC, Wierdsma NJ, van Bokhorst-de van der Schueren MA. Development and validation of a hospital screening tool for malnutrition: the short nutritional assessment questionnaire (SNAQ). Clin Nutr. 2005;24:75-82.

33. van Venrooij LMW, de Vos R, Borgmeijer-Hoelen AMMJ, Kruizenga HM, Jonkers-Schuitema CF, de Mol BAMJ. Quickand-easy nutritional screening tools to detect disease-related undernutrition in hospital in- and outpatient settings: A systematic review of sensitivity and specificity. e-SPEN. 2007;2:21-37.

34. Foss NB, Jensen PS, Kehlet H. Risk factors for insufficient perioperative oral nutrition after hip fracture surgery within a multimodal rehabilitation programme. Age Ageing. 2007;36:538-543.

35. Mullen JT, Davenport DL, Hutter MM, et al. Impact of body mass index on perioperative outcomes in patients undergoing major intra-abdominal cancer surgery. Ann Surg Oncol. 2008;15:2164-2172.

36. Kim JM, Park JH, Jeong SH, et al. Relationship between low body mass index and morbidity after gastrectomy for gastric cancer. Ann Surg Treat Res. 2016;90:207-212.

37. Hollander FM, van Pierre DD, de Roos NM, van de Graaf EA, Iestra JA. Effects of nutritional status and dietetic interventions on survival in cystic fibrosis patients before and after lung transplantation. J Cyst Fibros. 2014;13:212-218.

38. Sergi G, Perissinotto E, Pisent C, et al; ILSA Working Group. An adequate threshold for body mass index to detect underweight condition in elderly persons: the Italian Longitudinal Study on Aging (ILSA). I Gerontol A Biol Sci Med Sci. 2005;60:866-871.

39. Truong A, Hanna MH, Moghadamyeghaneh Z, Stamos MJ. Implications of preoperative hypoalbuminemia in colorectal surgery. World J Gastrointest Surg. 2016;8:353-362.

40. Kudsk KA, Tolley EA, DeWitt RC, et al. Preoperative albumin and surgical site identify surgical risk for major postoperative complications. JPEN J Parenter Enteral Nutr. 2003;27:1-9.

41. Ferguson M, Capra S, Bauer J, Banks M. Development of a valid and reliable malnutrition screening tool for adult acute hospital patients. Nutrition. 1999;15:458-464.

42. Kondrup J, Rasmussen HH, Hamberg O, Stanga Z; Ad Hoc ESPEN Working Group. Nutritional risk screening (NRS 2002): a new method based on an analysis of controlled clinical trials. Clin Nutr. 2003;22:321-336.

43. Nelson CL, Elkassabany NM, Kamath AF, Liu J. Low albumin levels, more than morbid obesity, are associated with complications after TKA. Clin Orthop Relat Res. 2015;473:3163-3172.

44. Wolfe RR. The underappreciated role of muscle in health and disease. Am J Clin Nutr. 2006;84:475-482.

45. Wolfe RR. Update on protein intake: importance of milk proteins for health status of the elderly. Nutr Rev. 2015;73(suppl 1):41-47.

46. Deutz NE, Safar A, Schutzler S, et al. Muscle protein synthesis in cancer patients can be stimulated with a specially formulated medical food. Clin Nutr. 2011;30:759-768.

47. Symons TB, Sheffield-Moore M, Wolfe RR, Paddon-Jones D. A moderate serving of high-quality protein maximally stimulates skeletal muscle protein synthesis in young and elderly subjects. J Am Diet Assoc. 2009;109:1582-1586.

48. Paddon-Jones D, Campbell WW, Jacques PF, et al. Protein and healthy aging. Am J Clin Nutr. 2015;101:1339S-1345S.

49. Jie B, Jiang ZM, Nolan MT, Zhu SN, Yu K, Kondrup J. Impact of preoperative nutritional support on clinical outcome in 
abdominal surgical patients at nutritional risk. Nutrition. 2012;28:1022-1027.

50. McClave SA, Kozar R, Martindale RG, et al. Summary points and consensus recommendations from the North American Surgical Nutrition Summit. JPEN J Parenter Enteral Nutr. 2013;37:99S-105S

51. Kuppinger D, Hartl WH, Bertok M, et al. Nutritional screening for risk prediction in patients scheduled for abdominal operations. Br J Surg. 2012;99:728-737.

52. Miller KR, Wischmeyer PE, Taylor B, McClave SA. An evidence-based approach to perioperative nutrition support in the elective surgery patient. JPEN J Parenter Enteral Nutr. 2013;37:39S-50S

53. Burden ST, Hill J, Shaffer JL, Campbell M, Todd C. An unblinded randomised controlled trial of preoperative oral supplements in colorectal cancer patients. J Hum Nutr Diet. 2011;24:441-448.

54. Grass F, Bertrand PC, Schäfer M, et al. Compliance with preoperative oral nutritional supplements in patients at nutritional risk—only a question of will? Eur J Clin Nutr. 2015;69:525-529.

55. Elia M, Normand C, Norman K, Laviano A. A systematic review of the cost and cost effectiveness of using standard oral nutritional supplements in the hospital setting. Clin Nutr. 2016;35:370-380.

56. Fukuda Y, Yamamoto K, Hirao M, et al. Prevalence of malnutrition among gastric cancer patients undergoing gastrectomy and optimal preoperative nutritional support for preventing surgical site infections. Ann Surg Oncol. 2015;22(suppl 3):S778-S785.

57. The Veterans Affairs Total Parenteral Nutrition Cooperative Study Group. Perioperative total parenteral nutrition in surgical patients. N Engl J Med. 1991;325:525-532.

58. Bozzetti F, Gavazzi C, Miceli R, et al. Perioperative total parenteral nutrition in malnourished, gastrointestinal cancer patients: a randomized, clinical trial. JPEN J Parenter Enteral Nutr. 2000;24:7-14.

59. Von Meyenfeldt MF, Meijerink WJ, Rouflart MM, Builmaassen MT, Soeters PB. Perioperative nutritional support: a randomised clinical trial. Clin Nutr. 1992;11:180-186.

60. Klein S, Kinney J, Jeejeebhoy K, et al. Nutrition support in clinical practice: review of published data and recommendations for future research directions. Clin Nutr. 1997;16:193-218.

61. Heyland DK, Montalvo M, MacDonald S, Keefe L, Su XY, Drover JW. Total parenteral nutrition in the surgical patient: a meta-analysis. Can J Surg. 2001;44:102-111.

62. Braunschweig CL, Levy P, Sheean PM, Wang X. Enteral compared with parenteral nutrition: a meta-analysis. Am J Clin Nutr. 2001;74:534-542.

63. Burden S, Todd C, Hill J, Lal S. Pre-operative nutrition support in patients undergoing gastrointestinal surgery. Cochrane Database Syst Rev. 2012;11:CD008879.

64. Stanga Z, Brunner A, Leuenberger $M$, et al. Nutrition in clinical practice-the refeeding syndrome: illustrative cases and guidelines for prevention and treatment. Eur J Clin Nutr. 2008;62:687-694.

65. Ljungqvist $\mathrm{O}$. Modulating postoperative insulin resistance by preoperative carbohydrate loading. Best Pract Res Clin Anaesthesiol. 2009;23:401-409.

66. Smith MD, McCall J, Plank L, Herbison GP, Soop M, Nygren J. Preoperative carbohydrate treatment for enhancing recovery after elective surgery. Cochrane Database Syst Rev. 2014:CD009161.

67. Harbis A, Perdreau S, Vincent-Baudry S, et al. Glycemic and insulinemic meal responses modulate postprandial hepatic and intestinal lipoprotein accumulation in obese, insulin-resistant subjects. Am J Clin Nutr. 2004;80:896-902.

68. Makarenkova VP, Bansal V, Matta BM, Perez LA, Ochoa JB. $\mathrm{CD} 11 \mathrm{~b}+/ \mathrm{Gr}-1+$ myeloid suppressor cells cause T cell dysfunction after traumatic stress. J Immunol. 2006;176:2085-2094.

69. Kemen M, Senkal M, Homann HH, et al. Early postoperative enteral nutrition with arginine-omega-3 fatty acids and ribonucleic acid-supplemented diet versus placebo in cancer patients: an immunologic evaluation of impact. Crit Care Med. 1995;23:652-659.

70. Evans DC, Hegazi RA. Immunonutrition in critically ill patients: does one size fit all? JPEN J Parenter Enteral Nutr. 2015;39:500-501.
71. Braga M, Gianotti L, Nespoli L, Radaelli G, Di Carlo V. Nutritional approach in malnourished surgical patients: a prospective randomized study. Arch Surg. 2002;137:174-180.

72. Marimuthu K, Varadhan KK, Ljungqvist O, Lobo DN. A metaanalysis of the effect of combinations of immune modulating nutrients on outcome in patients undergoing major open gastrointestinal surgery. Ann Surg. 2012;255:1060-1068.

73. Drover JW, Dhaliwal R, Weitzel L, Wischmeyer PE, Ochoa JB, Heyland DK. Perioperative use of arginine-supplemented diets: a systematic review of the evidence. J Am Coll Surg. 2011;212:385-399, 399.e1.

74. Heyland DK, Novak F, Drover JW, Jain M, Su X, Suchner U. Should immunonutrition become routine in critically ill patients? A systematic review of the evidence. JAMA. 2001;286:944-953.

75. Beale RJ, Bryg DJ, Bihari DJ. Immunonutrition in the critically ill: a systematic review of clinical outcome. Crit Care Med. 1999;27:2799-2805.

76. Marik PE, Zaloga GP. Immunonutrition in high-risk surgical patients: a systematic review and analysis of the literature. JPEN J Parenter Enteral Nutr. 2010;34:378-386.

77. Heys SD, Walker LG, Smith I, Eremin O. Enteral nutritional supplementation with key nutrients in patients with critical illness and cancer: a meta-analysis of randomized controlled clinical trials. Ann Surg. 1999;229:467-477.

78. Waitzberg DL, Saito H, Plank LD, et al. Postsurgical infections are reduced with specialized nutrition support. World J Surg. 2006;30:1592-1604.

79. Giger-Pabst U, Lange J, Maurer C, et al. Short-term preoperative supplementation of an immunoenriched diet does not improve clinical outcome in well-nourished patients undergoing abdominal cancer surgery. Nutrition. 2013;29:724-729.

80. Barker LA, Gray C, Wilson L, Thomson BN, Shedda S, Crowe TC. Preoperative immunonutrition and its effect on postoperative outcomes in well-nourished and malnourished gastrointestinal surgery patients: a randomised controlled trial. Eur J Clin Nutr. 2013;67:802-807.

81. Fujitani K, Tsujinaka T, Fujita J, et al; Osaka Gastrointestinal Cancer Chemotherapy Study Group. Prospective randomized trial of preoperative enteral immunonutrition followed by elective total gastrectomy for gastric cancer. Br J Surg. 2012;99:621-629.

82. Moya P, Soriano-Irigaray L, Ramirez JM, et al. Perioperative standard oral nutrition supplements versus immunonutrition in patients undergoing colorectal resection in an enhanced recovery (ERAS) protocol: a multicenter randomized clinical trial (SONVI Study). Medicine (Baltimore). 2016;95:e3704.

83. Moya P, Miranda E, Soriano-Irigaray L, et al. Perioperative immunonutrition in normo-nourished patients undergoing laparoscopic colorectal resection. Surg Endosc. 2016;30:4946-4953.

84. Thornblade LW, Varghese TK Jr, Shi X, et al. Preoperative immunonutrition and elective colorectal resection outcomes. Dis Colon Rectum. 2017;60:68-75.

85. Hegazi RA, Hustead DS, Evans DC. Preoperative standard oral nutrition supplements vs immunonutrition: results of a systematic review and meta-analysis. J Am Coll Surg. 2014;219:1078-1087.

86. Andersen HK, Lewis SJ, Thomas S. Early enteral nutrition within 24h of colorectal surgery versus later commencement of feeding for postoperative complications. Cochrane Database Syst Rev. 2006:CD004080.

87. Beier-Holgersen R, Boesby S. Influence of postoperative enteral nutrition on postsurgical infections. Gut. 1996;39:833-835.

88. Warren J, Bhalla V, Cresci G. Postoperative diet advancement: surgical dogma vs evidence-based medicine. Nutr Clin Pract. 2011;26:115-125

89. Lewis SJ, Andersen HK, Thomas S. Early enteral nutrition within $24 \mathrm{~h}$ of intestinal surgery versus later commencement of feeding: a systematic review and meta-analysis. J Gastrointest Surg. 2009;13:569-575

90. Gillis C, Carli F. Promoting perioperative metabolic and nutritional care. Anesthesiology. 2015;123:1455-1472.

91. Ferrando AA, Paddon-Jones D, Hays NP, et al. EAA supplementation to increase nitrogen intake improves muscle function during bed rest in the elderly. Clin Nutr. 2010;29:18-23. 
92. Beasley JM, LaCroix AZ, Neuhouser ML, et al. Protein intake and incident frailty in the Women's Health Initiative observational study. J Am Geriatr Soc. 2010;58:1063-1071.

93. Yeung SE, Hilkewich L, Gillis C, Heine JA, Fenton TR. Protein intakes are associated with reduced length of stay: a comparison between enhanced recovery after surgery (ERAS) and conventional care after elective colorectal surgery. Am J Clin Nutr. 2017;106:44-51.

94. Mariette C, De Botton ML, Piessen G. Surgery in esophageal and gastric cancer patients: what is the role for nutrition support in your daily practice? Ann Surg Oncol. 2012;19:2128-2134.

95. Doig GS, Simpson F, Sweetman EA, et al; Early PN Investigators of the ANZICS Clinical Trials Group. Early parenteral nutrition in critically ill patients with short-term relative contraindications to early enteral nutrition: a randomized controlled trial. JAMA. 2013;309:2130-2138.

96. Harvey SE, Parrott F, Harrison DA, et al; CALORIES Trial Investigators. Trial of the route of early nutritional support in critically ill adults. N Engl J Med. 2014;371:1673-1684.

97. Heidegger CP, Berger MM, Graf S, et al. Optimisation of energy provision with supplemental parenteral nutrition in critically ill patients: a randomised controlled clinical trial. Lancet. 2013;381:385-393.

98. Weimann A, Singer P. Avoiding underfeeding in severely ill patients. Lancet. 2013;381:1811.

99. Pradelli L, Mayer K, Muscaritoli M, Heller AR. n-3 fatty acidenriched parenteral nutrition regimens in elective surgical and ICU patients: a meta-analysis. Crit Care. 2012;16:R184.
100. Grass F, Benoit M, Coti Bertrand P, et al. Nutritional status deteriorates postoperatively despite preoperative nutritional support. Ann Nutr Metab. 2016;68:291-297.

101. Peterson SJ, Tsai AA, Scala CM, Sowa DC, Sheean PM, Braunschweig CL. Adequacy of oral intake in critically ill patients 1 week after extubation. J Am Diet Assoc. 2010;110:427-433.

102. Puthucheary ZA, Wischmeyer P. Predicting critical illness mortality and personalizing therapy: moving to multi-dimensional data. Crit Care. 2017;21:20.

103. Kalm LM, Semba RD: They starved so that others be better fed: remembering Ancel Keys and the Minnesota experiment. J Nutr. 2005;135:1347-1352.

104. Wischmeyer PE. Are we creating survivors...or victims in critical care? Delivering targeted nutrition to improve outcomes. Curr Opin Crit Care. 2016;22:279-284.

105. Cawood AL, Elia M, Stratton RJ. Systematic review and metaanalysis of the effects of high protein oral nutritional supplements. Ageing Res Rev. 2012;11:278-296.

106. Stratton RJ, Hébuterne $X$, Elia M. A systematic review and meta-analysis of the impact of oral nutritional supplements on hospital readmissions. Ageing Res Rev. 2013;12:884-897.

107. Stratton R, Green C, Elia M. Disease-Related Malnutrition: An Evidence-Based Approach to Treatment. Wallingford, UK: CABI Publishing; 2003.

108. Deutz NE, Matheson EM, Matarese LE, et al; NOURISH Study Group. Readmission and mortality in malnourished, older, hospitalized adults treated with a specialized oral nutritional supplement: a randomized clinical trial. Clin Nutr. 2016;35:18-26. 